\title{
$O$ incidente de resolução de demandas repetitivas e o microssistema de julgamento de questões repetitivas
}

The repetitive demands resolution incident and the repetitive issues judgment microsystem El incidente de resolución de reclamos repetitivos y el microsistema de juicio de problemas repetitivos

\section{Resumo}

Considerando a litigiosidade em massa que, além de congestionar o Poder Judiciário, gera insegurança jurídica por meio de decisões conflitantes sobre idêntica questão de direito, a Lei n. 13.105/2015 introduziu no ordenamento jurídico processual brasileiro mecanismos e técnicas destinadas a garantir estabilidade, coerência e integridade ao sistema jurisdicional. Dentre elas, o instituto do Incidente de Resolução de Demandas Repetitivas - IRDR, com o objetivo de promover segurança jurídica e tratamento isonômico às demandas judiciais que tratam da mesma questão de direito. Outrossim, criou-se um microssistema de julgamento de causas repetitivas, composto pelo IRDR e pelos recursos especial e extraordinário repetitivos. Esta pesquisa busca demonstrar a relevância do IRDR para o ordenamento processual brasileiro, apontar pontos de divergência doutrinária e as regras gerais que compõem o microssistema de julgamento de casos repetitivos. Para tanto, utilizou-se como método de investigação científica o dedutivo, com a coleta de dados por meio de pesquisa bibliográfica em livros didáticos, artigos, revistas científicas, legislação, jurisprudência e doutrinas.

Palavras-chave: Questões repetitivas; Incidente de resolução de demandas repetitivas; Microssistema.

\begin{abstract}
Considering the massive litigation that, in addition to congesting the Judiciary Power, generates legal uncertainty through conflicting decisions on the same issue of law, Law n. 13.105/2015 introduced into the Brazilian procedural legal system mechanisms and techniques designed to ensure stability, coherence and integrity to the jurisdictional system. Among them, the Institute of Repetitive Claims Resolution Incident - IRDR, with the objective of promoting legal certainty and equal treatment to the lawsuits that deal with the same question of law. Furthermore, a microsystem for the judgment of repetitive causes was created, comprising the IRDR and repetitive special and extraordinary appeals. This research seeks to demonstrate the relevance of the IRDR to the Brazilian procedural order, to point out points of doctrinal divergence and the general rules that make up the microsystem for judging repetitive cases. Therefore, the deductive method of scientific investigation was used, with data collection through bibliographic research in textbooks, articles, scientific journals, legislation, jurisprudence and doctrines.
\end{abstract}

Keywords: Repetitive questions; Repetitive demand resolution incident; Microsystem.

\section{Resumen}

Considerando el litigio masivo que, además de congestionar al Poder Judicial, genera inseguridad jurídica a través de decisiones contradictorias sobre un mismo tema de derecho, la Ley n. 13.105 / 2015 introdujo en el sistema legal procesal brasileño mecanismos y técnicas diseñadas para asegurar la estabilidad, coherencia e integridad del sistema jurisdiccional. Entre ellos, el Instituto de Resolución de Reclamaciones Repetitivas de Incidentes - IRDR, con el objetivo de promover la seguridad jurídica y la igualdad de trato a los juicios que traten la misma cuestión de derecho. Además, se creó un microsistema para la sentencia de causas repetitivas, integrado por el IRDR y los recursos especiales y extraordinarios repetitivos. Esta investigación busca demostrar la relevancia del IRDR para el orden procesal brasileño, señalar puntos de divergencia doctrinal y las reglas generales que conforman el microsistema para 
el juicio de casos repetitivos. Por lo tanto, se utilizó el método deductivo de investigación científica, con recolección de datos a través de la investigación bibliográfica en libros de texto, artículos, revistas científicas, legislación, jurisprudencia y doctrinas.

Palavras clave: Problemas repetitivos; Incidente de resolución de demanda repetitiva; Microsistema.

\section{Introdução}

Com o passar dos anos, observa-se que cada vez mais a produção, distribuição e a prestação de serviços acabam por impulsionar uma litigiosidade em massa, uma vez que a identificação de situações jurídicas homogêneas levam considerável parte da sociedade ao judiciário para a solução do conflito.

Diante do aumento exponencial de causas repetitivas, que resultam no congestionamento do Poder Judiciário, a Lei n. 13.105/2015 introduziu no ordenamento jurídico brasileiro o instituto do Incidente de Resolução de Demandas Repetitivas IRDR, disciplinado nos arts. 976 a 987 do Código de Processo Civil.

Conforme disposto no artigo 976, I e II, do CPC, caberá a instauração do incidente de resolução de demandas repetitivas quando houver, simultaneamente, a "efetiva repetição de processos que contenham controvérsia sobre a mesma questão unicamente de direito" e o "risco de ofensa à isonomia e à segurança jurídica".

Desse modo, o incidente objetiva a segurança jurídica e o tratamento isonômico a diferentes demandas judiciais que tratam da mesma questão de direito, por meio de tese jurídica única firmada a partir de um procedimento incidental.

Com a criação do IRDR, se fixou no Código de Processo Civil de 2015 um microssistema destinado à resolução de questões repetitivas, compreendida pelas técnicas de julgamento de recursos especiais e extraordinários repetitivos e o IRDR, conforme se verifica no art. 928, do CPC.

A pesquisa visa demonstrar pontos do incidente de resolução de demandas repetitivas que geraram entendimentos diversos entre doutrinadores, tais como, Sofia Temer, Luiz Guilherme Marinoni, Fredie Didier Jr., Leonardo Carneiro da Cunha, Daniel de Amorim Assumpção Neves e Marcos Cavalcanti, bem como a releveância desse instituto no ordenamento processual brasileiro e a funcionalidade do microssistema de julgamento de questões repetitivas.

Para tanto, inicia-se a pesquisa com a análise da questão da litigiosidade em massa e a solução encontrada pelo legislador processual ao fenômeno.

Na sequência, contextualizada a posição do IRDR dentro do microssistema de resolução de questões repetitivas, aprofundando seus objetivos, divergências doutrinárias sobre a natureza do incidente, ou seja, a utilização do sistema de causapiloto ou causa-modelo, apontando, ainda, as dimensões da tese jurídica firmada no IRDR.

Ao final, pretende-se abordar as regras gerais que compõem o microssistema de julgamento de questões repetitivas.

\section{Metodologia}

Para o constructo argumentativo, requer-se uma análise metodológica dedutiva, portanto, a utilização da revisão bibliográfica, legislativa e jurisprudencial em relação à temática do incidente de demandas repetitivas e seu microssistema.

As mudanças na legislação advém da necessidade de reajuste do Poder Judiciário na promoção adequada do acesso à justiça em razão da demanda massiva de ações, assim, a análise da lei que expressam as caterísticas do respectivo instituto do IRDR se faz pertinente.

Por meio do método dedutivo, de acordo com Eva Maria Lakatos e Marina de Andrade Marconi (2003, p. 92), pretende-se analisar a doutrina que discorrer sobre o IRDR de forma que se proceda a observância de quais os argumentos estão corretos ou incorretos ou as premissas são capazes de sustentar a conclusão em sua totalidade, ou seja, se o microssistema pretende promover a celeridade processual e o acesso à justiça para a obtenção da tutela de forma adequada, contribuindo com a diminuição do fluxo massivo de demandas. 


\section{Resultados e Discussão}

\subsection{A litigiosidade em massa}

A sociedade contemporânea, caracterizada pela globalização, pela distribuição seriada de produtos e serviços, pelo aumento do consumo humano, pela universalização do acesso a informação, o que eleva cada vez mais a conciência jurídica dos cidadãos, entre outros fatores, contribuem para o aumento da litigiosidade em massa (Didier Jr. \& Cunha, 2016, p. 584).

Posto que, não é raro que uma mesma situação, atinja a um só tempo, o direito de inúmeras pessoas que, passam a ingressar em juízo em busca de efetiva prestação jurisdicional. Assim, caracterizando uma litigiosidade repetitiva (Didier Jr. \& Cunha, 2016, p. 584). E com essa massificação de litígios, surge um grande problema, que é a insegurança jurídica diante de decisões conflitantes para uma mesma questão jurídica. Eduardo Cambi caracteriza esse fenômeno como "jurisprudência lotérica" (Cambi, 2001).

$\mathrm{O}$ autor explica que o fenômeno da jurisprudência lotérica "proporciona a falta de certeza do dreito, sendo causa de crise, pois é a certeza quanto à aplicação do direito que dá segurança à sociedade e aos individuos que a compõem" (Cambi, 2001, p. 110).

Na vigência do Código de Processo Civil de 1973, implemetaram-se mecanismos com o objetivo de agilizar o trâmite processual das demandas repetitivas, como o pedido de uniformização da interpretação da lei federal nos Juizados Especiais Federais (art. 14, $\S \S 5^{\circ}$ a $9^{\circ}$ da Lei 10.259/2001) e a inserção da ampliação da suspensão de liminares em casos repetitivos (art. $4^{\circ}$, § $8^{\circ}$ da Lei 8.437/1992, acrescentado pela MP 2.180-35/2001)(Roque, 2001). Posto que o Código a época havia sido pensado primordialmente para tutelar os conflitos de natureza individual, de modo a se mostrar inadequado as demandas repetitivas.

De igual modo, o microssistema de processo coletivo brasileiro, formado por normas processuais esparsas presentes no Código do Consumidor (Lei no 8.078/1990), na Lei de Ação Civil Pública (Lei no 7.347/1985) e na Lei de Mandado de Segurança Coletivo (Lei $\mathrm{n}^{\circ}$ 12.016/2009), que apresenta características próprias, tornam-se ineficientes diante dos direitos individuais homogêneos (Teixeira, 2015, p. 217). Daí, surge a necessidade de se empregar mecanismos e técnicas suficientes a alcançar as situações conflituosas repetitivas. Tendo em vista que as normas processuais devem propiciar meios eficazes à adequada resolução de conflitos (Temer, 2020, p. 32-34).

Como ensina Sofia Temer (2020, p. 37), "estes mecanismos têm em comum o fato de que, em vez de seguir o caminho da apreciação e julgamento individual e particularizado de cada um dos conflitos, adotam técnicas que permitem a resolução da questão de forma concentrada, em um ou alguns julgamentos, com a posterior aplicação da decisão aos casos seriados".

No mesmo sentido, Flávia Zanferdini e Alexandre Gomes, apontam que:

O processamento e o julgamento das demandas repetitivas ou de massa exige uma dogmática própria. Trata-se da necessidade de adaptação do processo civil às especificidades do litígio. Tais ações reclamam um tratamento processual próprio, um método de solução em bloco, de forma que escolhida uma ou mais ações como representativa do conflito homogeneizado (o leading case), uma vez proferida decisão nesta, a tese jurídica adotada deverá ter eficácia vinculativa e haverá de ser aplicada às demais ações repetitivas, de forma a preservar os príncipios da isonomia, da certeza do direito, da segurança, da previsibilidade e estabilidade da ordem jurídica (2016, p. 588).

Desse modo, a Lei n. 13.105/2015 introduziu no ordenamento jurídico brasileiro mecanismos processuais diferenciados, destinados ao aprimoramento do processo e julgamento dos casos repetitivos, entre eles o instituto do incidente de resolução de demandas repetitivas, disciplinado nos arts. 976 a 987 do Código de Processo Civil. 
Relevante se faz destacar que a nomenclatura "demandas repetitivas" pode variar, sendo comum para o mesmo fenômeno se empregar as denominações "demandas seriadas, massificadas, isomórficas, coletivadas, ações repetitivas etc" (Rodrigues, 2018, p. 28).

O CPC/2015 adotou o termo "casos repetitivos" (art. 928) e “demandas repetitivas" (arts. 976 e segs.), o que é alvo de críticas, pois, o termo "demanda" seria mais adequado a se referir a pretensões homogêneas, ou seja, atos de postulação constituídos de causas de pedir e pedidos similares (Temer, 2020, p. 61).

No entanto, conforme explica Sofia Temer (2020, p. 62), “para o sistema processual do CPC/2015, demandas repetitivas também compreendem demandas que não se referem a relações substanciais-modelo, não contêm causas de pedir e pedido similares (demandas heterogêneas, portanto), mas possuem áreas de homogeneidade, relativas a uma ou algumas das questões discutidas em juízo".

Marcos Cavalcanti, aponta que:

Em vez de "resolução de demandas repetitivas", o ordenamento brasileiro deveria ter adotado "resolução de questões repetitivas", pois, a similitude de causas de pedir e pedidos não é o fator determinante para a caracterização de um processo como repetitivo. Esses processos identificam-se no plano abstrato por discutirem, em larga escala, questões jurídicas de origem comum e homogêneas, que podem surgir ainda que não exista qualquer similaridade entre os elementos das demandas (Citado em Temer, 2020, p. 61).

Para José Carlos Barbosa Moreira (citado em Oliveira, 2018, p. 29), “o termo “questão” deve compreender quaisquer pontos controvertidos ou que suscitem dúvida no processo, ainda que não relacionados diretamente ao objeto deste, mas que aborde um ponto de fato ou de direito tratado no seu bojo".

Desse modo, entende-se a nomenclatura "questões repetitivas" como mais adequada quando se trata de IRDR, uma vez que, o que importa são as questões que se repetem nas demandas pois, pode haver repetição de uma questão exclusivamente processual, em casos totalmente distintos.

De qualquer modo, a exponencial litigiosidade em massa levando a decisões conflitantes para a mesma questão de direito, e assim a um resultado de imprevisibilidade e insegurança jurídica, foram os fatores que levaram o legislador a adotar o IRDR como mecanismo adequado a conferir uma solução mais eficiente, econômica, isonômica e segura das questões repetitivas.

\subsection{O IRDR no ordenamento processual brasileiro}

Como exposto, o instituto do IRDR foi pensado para solucionar o problema da exponencial multiplicação de processos sobre idêntica questão de direito. Haja vista que a grande problemática que envolve a massificação de processos sobre idêntica questão de direito é justamente decisões diversas, o que gera sensação de incerteza na aplicação do direito e insegurança jurídica.

Para Eduardo Cambi (2001, p. 110), “se é necessário assegurar aos juízes liberdade para interpretar o Direito, essa liberdade não pode ser absoluta, porque dá margem à existência do fenômeno da jurisprudência lotérica, o qual compromete a legitimidade do exercício do poder jurisdicional pelo estado-Juiz".

Diante desse fato, o IRDR foi inserido no ordenamento processual brasileiro, nos arts. 976 a 985 do CPC/2015, com a finalidade de fixar tese jurídica sobre determinada questão de direito, seja ela de direito processual ou de direito material, a ser aplicada aos processos pendentes e futuros, de modo a proporcionar uma prestação jurisdicional qualitativa, tempestiva e satisfatória. 
Nesse diapasão, observa-se a opinião de Luiz Guilherme Marinoni, Fredie Didier Jr., Leonardo Carneiro da Cunha, Luiz Manoel Gomes Jr. e Jussara Suzi Assis Borges Nasser Ferreira, quanto aos principais objetivos que levaram a inclusão do IRDR no direito processual brasileiro.

Para Fredie Didier Jr. e Leonardo Carneiro da Cunha (2016, p. 590), “o objetivo do IRDR e dos recursos repetitivos é conferir tratamento prioritário, adequado e racional às questões repetitivas. Tais instrumentos destinam-se, em outras palavras, a gerir e decidir os casos repetitivos.”

Na interpretação de Luiz Guilherme Marinoni (2019, p. 22):

O incidente de resolução de demandas repetitivas surgiu como meio para facilitar e acelerar a resolução de demandas múltiplas, que dependem da análise e decisão de uma "mesma" questão de direito (art. 976, I, CPC). Pretendeu-se igualmente evitar decisões diferentes para uma mesma questão, frisando-se que a instauração do incidente depende de "risco de ofensa à isonomia e à segurança jurídica" (art. 976, II, CPC).

Segundo Luiz Manoel Gomes Jr. e Jussara Suzi Assis Borges Nasser Ferreira (2018, p. 52), “o incidente possui três grandes finalidades: a) gerar uma interpretação uniforme; b) outorgar maior agilidade na entrega da prestação jurisdicional e; c) reduzir a quantidade de feitos em tramitação discutindo um mesmo tema jurídico".

De acordo com Ministro Alexandre de Moraes, o IRDR foi um grande ganho no ordenamento processual brasileiro, principalmente no tocante a celeridade processual, conforme se observa abaixo:

AGRAVO INTERNO. PRELIMINAR DE NÃO CONHECIMENTO. PRETENSÃO DEFENSIVA CONTRARIA A TESE JURÍDICA FIRMADA PELO TRIBUNAL EM SEDE DE IRDR. DEFINIÇÃO DO JUIZ NATURAL. ACUSADO MILITAR AO TEMPO DO CRIME. LICENCIAMENTO DAS FILEIRAS DAS FORÇAS ARMADAS. ALTERAÇÃO DA LOJM PELA LEI N. 13.774/2018. AVOCAÇÃO DO PROCESSO PELO MAGISTRADO DE CARREIRA DA JMU. IMPOSSIBILIDADE. AGRAVO NÃ̃O CONHECIDO. DECISÃO MONOCRATICA AGRAVADA MANTIDA POR MAIORIA. 1. A Lei no 13.77412018 trouxe alterações significativas à LOJM, especialmente na fixação do Juiz Natural quanto ao processo e ao julgamento de civil, quando lhe é atribuída a prática de crime de natureza militar. Essa definição competencial, de caráter monocrático, atribuída ao Juiz Federal da Justiça Militar, destina-se, em regra, ao agente (acusado que era civil ao tempo do crime, devendo-se, ainda, contextualizar eventuais delitos de insubmissão ou que envolvam oficiais. 2. A competência para o conhecimento, em sede judicial, e o subsequente julgamento de fatos configuradores de crime castrense, atribuído unicamente à praça, recai sobre o Colegiado de $1^{\circ}$ grau (CPJ), considerando como fator determinante a qualidade pessoal do agente (praça - militar da ativa), no momento da prática ilícita. Dessa maneira, o seu superveniente licenciamento das Forças Armadas não induz qualquer modificação no aspecto competencial. 3. A base principiológica da Justiça Militar da União IJMU) é estruturada, sobretudo, no instituto do Escabinato. O seu aparelhamento permite a salvaguarda dos valores predominantes no estamento militar, sob os quais as Forças Armadas se fundamentam. Nessa perspectiva, a conduta configuradora de crime castrense estará sujeita ao adequado dimensionamento punitivo. A violação à Lei Penal Militar traz consideráveis repercussões no seio da tropa. Esse formato de prestação jurisdicional permite a intensa conjugação do conhecimento Jurídico com a experiência adquirida na caserna. Dai exsurge a importância da preservação da essência da JMU, estampada na instituição do Escabinato. 4. A fixação da competência do Colegiado 'a quo", com o consequente retorno dos autos à Primeira Instância. Impõe regularidade à Ação Penal Militar, sob o prumo do Devido Processo Legal. 5. O IRDR exsurge como instrumento legal que contextualiza a celeridade processual idealizada para a desobstrução da jurisdição recursal. no tocante às demandas repetitivas. Por isso, habilmente, sob a delimitação de seu escopo. lixado na tese jurídica aprovada pelo Tribunal, compete ao Relator promover a solução de Processos que se adequem ao âmbito de seu alcance. 6. A via do Agravo Interno é inapta para o intuito de desconstituir a tese firmada pelo Tribunal no âmbito de IRDR. Tampouco se presta para fomentar a reanálise dos mecanismos instrumentalizados no referido Incidente, os quais objetivam, sobretudo, a segurança jurídica e a celeridade processual. Assim, o conhecimento dessa espécie recursal encampa estratégia protelatória, medida indesejável e merecedora de resposta proporcional. Nessa perspectiva, a solução indicada é o não conhecimento do Agravo Interno. Decisão por maioria. Nesse contexto, incide a regra segundo a qual não haverá declaração de nulidade quando não demonstrado o efetivo prejuízo causado à parte (pas de nullité sans grief). Pertinentes, a propósito dessa temática, as lições de ADA, SCARANCE e MAGALHÃES: "Sem ofensa ao sentido teleológico da norma não haverá prejuízo e, por isso, o reconhecimento da nulidade nessa hipótese constituiria consagração de um formalismo exagerado e inútil, que sacrificaria o objetivo maior da atividade jurisdicional" (As nulidades no processo penal, p. 27, 12. ed., 2011, RT). Diante do exposto, com base no art. $21, \S 1^{\circ}$, do Regimento Interno do Supremo Tribunal 
Federal, INDEFIRO a ordem de HABEAS CORPUS. Publique-se. Brasília, 22 de janeiro de 2021. Ministro Alexandre de Moraes Relator Documento assinado digitalmente. (STF - HC: 195703 RS 0111075 57.2020.1.00.0000, Relator: Alexandre de Moraes, Data de Julgamento: 22/01/2021, Data de Publicação: 27/01/2021) (grifo nosso).

De qualquer forma, comum é o entendimento de que o IRDR privilegia a segurança jurídica, valorizando a previsibilidade e a estabilidade das decisões judiciais acerca da mesma questão de direito, assim, atenuando os efeitos da jurisprudência lotérica.

O art. 976 e seguintes do CPC, regulam o IRDR, estabelecendo que existindo processos repetitivos sobre uma mesma questão de direito, que ofereçam risco de ofensa à isonomia e à segurança jurídica, o incidente será instaurado perante o Presidente do Tribunal de acordo com sua competência e jurisdição.

Admitido o IRDR, todos os processos em curso na jurisdição do Tribunal afetado, com idêntica questão de direito, serão suspensos até a fixação da tese jurídica pelo Tribunal, tendo este o prazo de um ano para julgar o incidente.

Julgado o incidente, a tese jurídica firmada pelo Tribunal será aplicada aos processos individuais ou coletivos, presentes e futuros que tenham em seu bojo idêntica questão de direito, seja de direito material ou processual. E, caso não observada a tese adotada no incidente, caberá reclamação, nos termos do $§ 1^{\circ}$, art. 985 , do CPC.

O procedimento do IRDR, deveras simples, não passa incólume às críticas. Zulmar Duarte de Oliveira Jr. (2013 como citado em Oliveira, 2018, p. 110), questiona a validade do incidente como instrumento uniformizador de questões repetitivas em âmbito regional ou estadual, sob o argumento de que a sua sistemática possibilita decisões distintas por tribunais distintos, sobre a mesma questão.

Por óbvio que a problemática levantada realmente existe. Entretanto, como observa Fernando Antônio Oliveira (2018, p.110) "seria bem pior o quadro de excessiva dispersão que deu ensejo à criação do IRDR".

Noutro norte, se faz necessário destacar que o próprio CPC criou mecanismos para combater esses efeitos, como o pedido a ser dirigido ao Superior Tribunal de Justiça ou ao Supremo Tribunal Federal, de suspensão nacional dos processos que versem sobre a questão objeto do incidente já instaurado (art. 982, §3º), o manejo de Recurso Especial ou Recurso Extraordinário sobre a tese firmada em IRDR - o que resultará na aplicação de uma tese única para todo o país -, bem como, a própria afetação de um recurso excepcional pela sistemática dos repetitivos, quando diferentes tribuinais fixarem teses diferentes para uma mesma questão jurídica (Oliveira, 2018, p. 110).

Em consulta ao Banco Nacional de Demandas Repetitivas e Precedentes Obrigatórios do Conselho Nacional de Justiça, observa-se que, até o momento, foram julgados um total de 301 (trezentos e um) incidentes. Dos quais, 200 (duzentos) pela Justiça Estadual, 29 (vinte e nove) pela Justiça Federal e 72 (setenta e dois) pela Justiça do Trabalho.

Se considerar-se que se passaram apenas 06 (seis) anos desde que o IRDR foi inserido no ordenamento processual brasileiro, bem como o fato de que o legislador estipulou o prazo de 01 (um) ano para o seu julgamento, conclui-se que o caminho percorrido até então tenha sido benéfico. Afinal, são mais de trezentas teses jurídicas fixadas por tribunais estaduais e regionais, servindo como padrão decisório às demandas com idêntica questão de direito. O que possibilita a redução da atividade repetitiva, bem como o envio aos tribunais superiores de processos que podem receber uma decisão justa e equânime no juízo de primeiro grau.

\subsection{Controvérsias acerca da natureza do IRDR}

Verifica-se muitos posicionamentos divergentes sobre vários aspectos do IRDR, sendo um deles quanto a definição da sua natureza, o que será analisado a seguir.

Segundo Sofia Temer (2020, p. 67-68): 
A definição da natureza do incidente é tarefa complexa, porque a lei não é clara a respeito de um aspecto essencial para determiná-la: saber se o incidente compreenderá o julgamento da "causa", ou seja, do conflito subjetivo que levou à sua instauração, ou se apenas haverá a resolução pontual da questão de direito, em abstrato, fixando-se a tese jurídica sem a resolução de conflito subjetivos.

O debate doutrinário gira em torno exatamente da questão de, se o IRDR leva ao julgamento da lide ou se apenas fixa a tese jurídica. Nesse interim, se faz importante destacar os dois sistemas de resolução de causas repetitivas conhecidas do direito estrangeiro, quais sejam, o da causa-piloto e o da causa-modelo.

Conforme ensinam Didier e Cunha (2016, p. 593), no sistema da causa-piloto, o órgão jurisdicional seleciona um caso para julgar, fixando a tese a ser seguida nos demais. Já na causa-modelo, instaura-se um incidente apenas para fixar a tese a ser seguida, não havendo a escolha de uma causa a ser julgada.

Para Daniel de Amorim, o sistema adotado no IRDR é inovador, pois não se assemelha a nenhum sistema conhecido no direito estrangeiro, dispondo:

Entendo que o IRDR é um sistema inovador, já que não se adotou plenamente nenhum dos sistemas conhecidos no direito estrangeiro. Julgará o recurso ou ação e fixará a tese jurídica. Parece ser o sistema de causa-piloto, mas não é, porque exige a formação de um incidente processual, não sendo, portanto, a tese fixada na "causa-piloto". E não é um procedimento-modelo porque o processo ou recurso do qual foi instaurado o IRDR é julgado pelo próprio órgão competente para o julgamento do incidente (2019, p. 1.513).

Já Didier e Cunha (2016, p. 596), entendem que se deve observar as intercorrências até o julgamento do caso repetitivo, na hipótese de desistência ou abandono, o julgamento do IRDR ou do recurso repetitivo configura uma causamodelo. Abstraída essa hipótese, o que se tem é uma causa-piloto, com julgamento do caso.

Sofia Temer adota a seguinte posição:

O incidente de resolução de demandas repetitivas apenas resolve a questão de direito, fixando a tese jurídica, que será posteriormente aplicada tanto nos casos que serviram como substrato para a formação do incidente, como nos demais casos pendentes e futuros. Entendemos, portanto, que no incidente não haverá julgamento de "causa-piloto", mas que será formado um "procedimento-modelo" (2020, p. 71).

De acordo com Marcos Cavalcanti:

$\mathrm{O}$ art. 978, parágrafo único do CPC/2015 deixa claro que há um desmembramento de julgamento ao dizer que o órgão colegiado imcumbido de julgar o incidente julgará igualmente a causa pendente. 'Julgar igualmente' não é o mesmo que 'julgar simultaneamente'. (...) São duas as decisões, uma abstrata, que julga e fixa a tese no IRDR, e outra concreta e posterior, que decide a lide posta no processo pendente no tribunal e essa divisão cognitiva fica evidente quando o NCPC permite a interposição autônoma de recurso especial ou extraordinário contra a decisão de mérito do IRDR, sem necessariamente, ter havido recurso contra a decisão que aplica a tese ao caso pendente no tribunal (citado em Temer, 2020, p. 71).

Marcelo Eugênio Feitosa Almeida (2017, p. 159), em estudo feito acerca dos regimes de IRDR adotados pelos Tribunais Regionais Federais, aponta que os TRF's não têm mantido uniformidade quanto ao tema, mesmo que com uma tendência à adoção de um modelo predominantemente de causa-piloto, de certa forma, porque é o sistema adotado nos recursos especial e extraordinário repetitivos, reconhecem a impossibilidade de seguir tal modelo em todas as situações. De modo a adotarem uma espécie de modelo híbrido.

Observa-se que cada tribunal tem adotado procedimentos próprios em seus regimentos internos, levando-se em conta as peculiaridades de cada um, objetivando-se o aperfeiçoamento dos resultados. 
De todo modo, independentemente se adotado o sistema de causa-piloto ou de causa-modelo, a natureza jurídica do IRDR é de incidente, como bem indica seu nome. O que leva a outro ponto de divergência doutrinária.

Doutrinadores, como Alexandre Câmara, Fredie Didier Jr., Leonardo Carneiro da Cunha, e Antonio do Passo Cabral, defendem que para a instauração do incidente, é indispensável a tramitação de pelo menos um processo perante o tribunal, seja ele de competência originária, de remessa necessária ou de recurso.

Nesse sentido, é o enunciado 344 do Fórum Permanente de Processualistas Civis: “A instauração do incidente pressupõe a existência de processo pendente no respectivo tribunal”.

Para Alexandre Câmara, há necessidade de que a causa esteja pendente no tribunal porque o tribunal vai julgar também o caso concreto:

Terceiro requisito, que não está expresso na lei mas resulta necessariamente do sistema é que já haja pelo menos um processo pendente perante o tribunal (...) É que, como se verá melhor adiante, uma vez instaurado o IRDR, o processo em que tal instauração ocorra será afetado para julgamento por órgão a que se tenha especificamente atribuído a competência para conhecer do incidente, o qual julgará o caso concreto como uma verdadeira causapiloto (Câmara, 2020, p. 109).

De acrodo com Didier e Cunha (2016, p. 625) que:

Se não houver caso em trâmite no tribunal, não se terá um incidente, mas um processo originário. E não é possível ao legislador ordinário criar comptências originárias para os tribunais. (...) O legislador ordinário pode - e foi isso que fez o CPC - criar incidentes processuais para causas originárias e recursais que tramitem nos tribunais, mas não lhe cabe criar competências originarias para os tribunais. É também por isso que não se permite a instauração do IRDR sem que haja causa tramitando no trbunal.

No mesmo sentido, Antonio do Passo Cabral (2020, p. 109), aponta que tendo em vista o art. 978, parágrafo único, “a intenção do legislador é claramente de que o IRDR somente possa ser suscitado na pendência de processo no tribunal, ou seja, já depois de proferidas decisões na primeira instância".

Por outro lado, Sofia Temer defende a inconstitucionalidade do parágrafo único do art. 978:

O parágrafo único do art. 978, com todas as vênias, corresponde a um grande equívoco no processo legislativo. É que este dispositivo foi incluído no novo CPC quando o projeto retornou do Senado Federal no final de 2014. A norma não constava do projeto aprovado no Senado em 2010, tampouco na versão aprovada na Câmara dos Deputados em 2014. Nessas condições, o parágrafo único do art. 978 só poderia ser copreendido como constitucional se se tratasse das chamadas 'emenda de redação', i.e., mudanças estilísticas com a finalidade de aperfeiçoamento gramatical e sintático, mas sem alteração de conteúdo. Não é o caso (Temer, 2020, p. 111).

\section{Outrossim, Marcos Cavalcanti:}

Este dispositivo padece de inconstitucionalidade formal e material. É inconstitucional formalmente, pois ele não encontra qualquer enunciado normativo correspondente no Anteprojeto, no Projeto do Senado e no Projeto da Câmara. (...) O parágrafo único do art. 978 do NCPC vincula a competência para julgamento do recurso, remessa necessária ou do processo originário, usurpando a competência dos tribunais de estabelecerem suas atribuições internas por meio do regimento interno (citado em Temer, 2020, p. 111).

Noutro norte, o Fórum da Escola Nacional de Formação e Aperfeiçoamento de Magistrados (ENFAM) editou o enunciado n' 22: "A instauração do IRDR não pressupõe a existência de processo pendente no respectivo tribunal".

Para Sofia Temer, "o melhor entendimento acerca da questão é o que permite a instauração do incidente sem que haja, necessariamente, causa pendente de julgamento no tribunal” (2020, p. 110). 
Nesse diapasão, Aluisio Gonçalves de Castro e Sofia Temer entendem que aguardar até que haja processos no Tribunal pode significar desperdício de atividade jurisdicional, de modo que haveria maior celeridade e economia se desde logo tivesse sido instaurado o incidente (2020, p. 235).

\subsection{O IRDR e a formação de precedente}

Pelo que se depreende da leitura do art. 985, do CPC/2015, a decisão do IRDR se trata de uma tese jurídica com força vinculante, uma vez que destinada a servir como padrão decisório a casos pendentes e futuros.

Na visão de doutrinadores como Sofia Temer, José Miguel Garcia Medina, Alexandre Freire e Alonso Freire, seria essa tese jurídica um precedente, caso se entenda que um precedente é a decisão capaz de servir como padrão decisório de casos futuros envolvendo fatos ou questões jurídicas idênticas ou similares.

Nessa perspetiva, importante se faz mencionar que nem todas as decisões proferidas no IRDR serão consideradas precedentes. Nesse sentido, Sofia Temer entende que “a eficácia prevista nos arts. 927, III, e 985 apenas se justifica caso tenham sido observados os procedimentos e prerrogativas previstas para legitimar a decisão, notadamente as de participação no debate e de fundamentação exaustiva" (2020, p. 235).

Para Luiz Guilherme Marinoni, é preciso que a decisão enfrente todos os principais argumentos relacionados à questão de direito posta na moldura do caso concreto, ao passo que os contornos de um precedente podem surgir a partir da análise de vários casos, ou melhor, mediante uma construção da solução judicial da questão de direito que passa por diversos casos (2018, p. 87).

Conforme enunciado 606, do Fórum Permanente de Processualistas Civis, "deve haver congruência entre a questão objeto da decisão que admite o incidente de resolução de demandas repetitivas e a decisão final que fixa a tese".

Desse modo, entende-se que para que a tese jurídica firmada no IRDR possa ser considerada um precedente, é necessário que o tribunal tenha observado todas as regras e procedimentos previstos no CPC/2015, quais sejam, as de publicidade, de participação, e de exaustivo debate.

Noutro norte, Daniel Mitidiero entende que a tese jurídica firmada no IRDR não se trata de precedente, pois apenas as cortes superiores formam precedentes, por sua função de dar unidade ao direito (citado em Temer, 2020, p. 234).

Para Luiz Guilherme Marinoni, no IRDR não há formação de precedente, pois apenas resolve casos idênticos, criando uma solução para a questão replicada nas múltiplas ações pendentes (2016, p. 591).

Já Humberto Theodoro Jr., endende que a formação de precedentes obrigatórios é um dos objetivos do IRDR, conforme se observa no trecho abaixo transcrito:

O incidente autorizado pelo art. 976 do CPC é um instrumento processual destinado a produzir eficácia pacificadora de múltiplos litígios mediante estabelecimento de tese aplicável a todas as causas em que se debata a mesma questão de direito. Com tal mecanismo se intenta implantar uniformidade de tratamento judicial a todos os possíveis litigantes colocados em situação igual àquela disputada no caso padrão. Cumpre-se por seu intermédio duplo objetivo: a par de racionalizar o tratamento judicial das causas repetitivas (arts. 976; 980 a 984), o incidente visa formar precedente de observância obrigatória (art. 985) (Theodoro Jr., 2020).

De qualquer modo, incontroverso é o fato de que a tese jurídica firmada no IRDR tem força vinculativa. Incidindo tal eficácia sob o tribunal que o apreciou, seus órgãos e juízos inferiores a ele estarão subordinados.

Embora o art. $985, \S 2^{\circ}$ do CPC/2015 disponha que " $\$ 2^{\circ}$ Se o incidente tiver por objeto questão relativa a prestação de serviço concedido, permitido ou autorizado, o resultado do julgamento será comunicado ao órgão, ao ente ou à agência reguladora competente para fiscalização da efetiva aplicação, por parte dos entes sujeitos a regulação, da tese adotada”, Sofia 
Temer defende que não há subordinação direta de tais entes e órgãos à tese fixada, ficando a Administração Pública vinculada apenas nos limites dos conflitos subjetivos de que seja parte (Temer, 2020, p. 246-247).

Em sentido contrário, Hermes Zaneti Jr. defende que a vinculação envolve a todos os aplicadores do direito, inclusive nas relações privadas. Estando a vinculação ainda mais forte para a Administração Pública, pois esta deve seguir os precedentes vinculantes no novo CPC com a força normativa da própria lei, sob pena de ofensa ao princípio da legalidade (citado em Temer, 2020, p. 246).

Para Sofia Temer, o disposto no art. $985, \S 2^{\circ}$ do CPC/2015 deve ser entendido como um mecanismo que confere uma eficácia persuasiva em relação à administração pública. Visto que, a comunicação do resultado do julgamento do incidente pode levar à alteração na conduta dos prestadores de serviço público (2020, p. 246-247).

De qualquer modo, a fixação da tese jurídica pelo tribunal gera menos decisões conflitantes, reduzindo significativamente a insegurança jurídica dos jurisdicionados. Ainda, o próprio sistema normativo processual brasileiro, estabece uma série de normas que agilizam o julgamento das demandas com a mesma questão de direito, a partir da fixação da tese.

Não obstante, a tese jurídica firmada no IRDR pode ser revista, nos termos do art. 986, do CPC/2015. E caso isso ocorra, a aplicação da modulação de efeitos é recomendável para se controlar os efeitos adversos, estabelencedo-se um regime de transição. Tendo em vista que, a decisão do IRDR atinge uma significativa quantidade de processos, destinadas a demandas repetitivas.

\subsection{O microssistema de julgamento de questões repetitivas}

A exponencial multiplicação de processos sobre idêntica questão de direito é um fenômeno que torna cada vez mais difícil a efetiva, justa e razoável prestação jurisdicional. Embora o Poder Judiciário tenha aumentado em muito sua produtividade, a crescente demanda por acesso a justiça, acaba por suplantá-la.

Nesse contexto, o legislador buscou implantar mecanismos e técnicas de gerenciamento destinadas a resolução das questões repetitivas, sendo uma delas a sistematização de instrumentos processuais, como é o caso do microssistema de julgamento de questões repetitivas, como se observa no art. $928^{1}$, do CPC/2015.

Nesse sentido, a Ministra Nancy Andrighi, no julgamento do Recurso Especial no 1.846.109 - Sp (2019/0216474-5), afirma:

Embora situados em espaços topologicamente distintos e de ter havido previsão específica do procedimento de distinção em IRDR no PLC 8.046/2010, posteriormente retirada no Senado Federal, os recursos especiais e extraordinários repetitivos e o IRDR compõem, na forma do art. 928, I e II, do novo CPC, um microssistema de julgamento de questões repetitivas, devendo o intérprete promover, sempre que possível, a integração entre os dois mecanismos que pertencem ao mesmo sistema de formação de precedentes vinculantes. ${ }^{2}$

No mesmo sentido, o Ministro João Otávio de Noronha, em outro julgamento discorre sobre o tema:

AGRAVO INTERNO EM PETIÇÃO. RECLAMAÇÃO. INCIDENTE DE RESOLUÇÃO DE DEMANDAS REPETITIVAS (IRDR). INSTITUTO AFETO À COMPETÊNCIA JURISDICIONAL DE TRIBUNAIS DE

\footnotetext{
${ }^{1}$ Art. 928. Para os fins deste Código, considera-se julgamento de casos repetitivos a decisão proferida em:

I - incidente de resolução de demandas repetitivas;

II - recursos especial e extraordinário repetitivos.

Parágrafo único. O julgamento de casos repetitivos tem por objeto questão de direito material ou processual.

${ }^{2}$ Superior Tribunal de Justiça. Recurso Especial nº 1846109/SP. Fundação Saúde x Valeria de Fatima Figueiredo. Relator: Ministra Nancy Andrighi, Brasília, DF,10 de dezembro de 2019, Data de Publicação: DJe 13/12/2019. Disponível em < https://scon.stj.jus.br/SCON/> . Acesso em: 15 de abril de 2021.
} 
SEGUNDA INSTÂNCIA (ESTADUAIS OU REGIONAIS FEDERAIS). INSTAURAÇÃO DIRETA NO SUPERIOR TRIBUNAL DE JUSTIÇA. POSSIBILIDADE RESTRITA. NECESSIDADE DE OBSERVÂNCIA DOS REQUISITOS (ART. 976 DO CPC). JUÍZO DE ADMISSIBILIDADE NÃO ULTRAPASSADO. NÃO CABIMENTO DA INSTAURAÇÃO DO INSTITUTO. 1. O novo Código de Processo Civil instituiu microssistema para o julgamento de demandas repetitivas - nele incluído o IRDR, instituto, em regra, afeto à competência dos tribunais estaduais ou regionais federal -, a fim de assegurar o tratamento isonômico das questões comuns e, assim, conferir maior estabilidade à jurisprudência e efetividade e celeridade à prestação jurisdicional. 2. A instauração de incidente de resolução de demandas repetitivas diretamente no Superior Tribunal de Justiça é cabível apenas nos casos de competência recursal ordinária e de competência originária e desde que preenchidos os requisitos do art. 976 do CPC. 3. Quando a reclamação não ultrapassa o juízo de admissibilidade, não cabe a instauração do incidente de demandas repetitivas no Superior Tribunal de Justiça. 4. Agravo interno desprovido. (AgInt na Pet 11.838/MS, Rel. Ministra LAURITA VAZ, Rel. p/ Acórdão Ministro JOÃO OTÁVIO DE NORONHA, CORTE ESPECIAL, julgado em 07/08/2019, DJe 10/09/2019)

O IRDR, inserido no rito dos repetitivos, muito tem a contribuir com esse microssistema. Haja vista que, uma de suas grandes vantagens é o fato de poder ser instaurado no Tribunal de Justiça ou Tribunal Regional Federal, sem a necessária participação dos Tribunais Superiores.

Importante se faz destacar que os instrumentos de julgamento de casos repetitivos compõem, uma regulação híbrida, integrando o microssistema de gestão de casos repetitivos e o microssistema de formação concentrada de precedentes obrigatórios (Didier Jr. \& Cunha, 2016, p. 599).

Para maior aclaramento, entende-se um microssistema como um conjunto de normas que se relacionam uma com as outras e, de forma conjunta, buscam alcançar um objetivo.

Pelas características apresentadas, diz-se que há no microssistema de resolução de questões repetitivas a possibilidade de aplicação dos instrumentos previstos em um e inexistentes no outro, de modo que se complementam, desde que não haja expressa vedação legal.

É como entende a Ministra Nancy Andrighi, conforme trecho do julgamento do Recurso Especial $\mathrm{n}^{\circ} 1.846 .109-\mathrm{Sp}$ (2019/0216474-5):

Os vetores interpretativos que permitirão colmatar as lacunas eventualmente existentes em cada um desses mecanismos, de modo a integrá-los em um verdadeiro microssistema de julgamento de questões repetitivas, deverão ser, a meu juízo, a inexistência de vedação expressa no texto do novo CPC que inviabilize a integração entre os instrumentos e, ainda, a inexistência de ofensa a um elemento essencial do respectivo instituto, o que equivaleria a desnaturá-lo (Recurso Especial no 1846109/SP, 2019, dezembro).

No mesmo sentido, o Fórum Permanente de Processualistas Civis aprovou o Enunciado 345 “O incidente de resolução de demandas repetitivas e o julgamento dos recursos extraordinários e especiais repetitivos formam um microssistema de solução de casos repetitivos, cujas normas de regência se complementam reciprocamente e devem ser interpretadas conjuntamente".

Nota-se, que o legislador buscou instituir um mecanismo suficiente para auxiliar na prestação jurisdicional de forma justa, efetiva e adequada.

Os recursos extraordinário e especial repetitivos e o IRDR reúnem características e objetivos próprios, que na visão de Didier Jr. e Cunha (2016, p. 673), se destinam principalmente a: (i) gerir casos repetitivos; e, (ii) formar precedentes obrigatórios.

Inegável que existem diferenças entre os institutos que compõem o microssistema de julgamento de casos repetitivos, porém, nesse atigo se pretende enumerar as regras comuns a ambos. E, conforme sistematiza Didier Jr. e Cunha (2016, p. 599624), são elas: 
- A suspensão dos processos em que se discute a mesma questão de direito (arts. 981, I, e1.037, II, do CPC);

- Exercício do direito à distinção e revogação da suspensão indevida (art. 1.037, §§8 a 13);

- Possibilidade à desistência do processo, antes de proferida a sentença (art. $\left.1.040, \S^{\circ} \mathrm{a} 3^{\circ}\right)$;

- Comunicação da instauração e da decisão ao órgão, ente, ou agência reguladora, no caso de questão relacionada à prestação de serviço objeto de concessão, permissão ou autorização (arts. 985, §2 e 1.040, IV, do CPC);

- Possibilidade de exame de mérito mesmo em caso de abandono do proceso ou recurso dos quais se originarem o IRDR ou o recurso repetitivo (art. $976, \S 1^{\circ}$, do CPC);

- Regramento sobre a competência para a apreciação de pedidos de tutela de urgência (art. $982, \S 2^{\circ}$ e 1.029 , §5 $5^{\circ}$, III, do CPC);

- Seleção de dois ou mais casos representativos da controvérsia (art. 1.036, §§ $1^{\circ}$ e $5^{\circ}$, do CPC);

- Identificação da questão a ser submetida a julgamento (art. 1.037, I, do CPC);

- Vinculação da tese jurídica produto do julgamento aos processos pendentes, sobrestados ou não (arts. 985, I e 1.040, I e III, do CPC);

- Divulgação e publicidade dos IRDR's e recursos repetitivos instaurados e julgados, assim como das teses fixadas (art. 979 do CPC, inclusive seu $\S 3^{\circ}$ );

- Ampla participação de interessados e amicus curiae (arts. $983, \S \S 1^{\circ}$ e $2^{\circ}$, e 1.038 , I e II, do CPC);

- Intervenção do Ministério Público, quando não for parte (arts. 976, §2º e 1.038, III, do CPC);

- Possibilidade de interposição de recurso pelo amicus curiae em face da decisão de mérito tanto do IRDR quanto dos recursos repetitivos (art. 138, § $3^{\circ} \mathrm{c} / \mathrm{c}$ art. 928, do CPC);

- Procedimento para revisão/superação da tese jurídica (art. 986, do CPC);

- Prazo de um ano para julgamento (arts. 980 e $1.037, \S 4^{\circ}$, do CPC);

- Prioridade de julgamento (arts. 980 e $1.037, \S 4^{\circ}$, do CPC) e exclusão da ordem cronológica de julgamento (art. 12, $\S 2^{\circ}$, III, do CPC).

Destaca-se, que algumas das regras acima enumeradas não estão expressamente previstas no IRDR, porém, a interpretação conjunta dos institutos que compõem o microssistema de julgamento de questões repetitivas, leva à integração das normas, suprindo as lacunas existentes no incidente.

Cita-se como exemplo a adoção do procedimento previsto no art. 1.037, §§ $8^{\circ}$ a 13 , do CPC/2015, caso seja aplicada erroneamente a suspensão a processo distinto.

Nesse sentido, é como entende o Fórum Permanente de Processualistas Civis no enunciado 481, “O disposto nos $\S \S 9^{\circ}$ a 13 do art. 1.037 aplica-se, no que couber, ao incidente de resolução de demandas repetitivas".

Outros exemplos, são: i) a escolha de no mínimo dois processos para fins de afetação; ii) os critérios para a escolha dos sujeitos que deverão conduzir o debate que precede a fixação da tese; e, iii) a identificação da questão a ser submetida a julgamento.

Como se observa, a interpretação sistemática do IRDR e dos recursos extraordinário e especial repetitivos formam um microssistema de julgamento de questões repetitivas, que possibilita a complementariedade dos institutos, servindo para administrar e julgar as demandas repetitivas, bem como preservar a jurisprudência.

Em linhas gerais, as normas que orientam os institutos integrantes do microssistema de julgamento de questões repetitivas, se bem interpretadas e integradas, são capazes de assegurar a isonomia, a segurança jurídica e celeridade processual. Tendo em vista que, como ensina José Joaquim Gomes Canotilho, “a norma é o resultado do processo hermenêutico, cabendo ao intérprete atribuir significação aos enunciados linguísticos” (citado em Cambi, 2001, p. 109).

\section{Conclusões}

Apenas seis anos se passaram desde a entrada em vigor do novo Código de Processo Civil, e com ele uma de suas grandes inovações, o incidente de resolução de demandas repetitivas. 
Como exposto, ao longo dos anos muitas divergências surgiram quanto a compreensão de vários aspectos do IRDR. No entanto, convém destacar que a litigiosidade em massa e a necessidade de tratamento isonômico aos jurisdicionados, foram fatores determinantes para a inserção do IRDR do ordenamento jurídico processual brasileiro.

Proporcionar segurança jurídica por meio de decisões harmônicas e equânimes, aplicáveis a processos pendentes e futuros, que tratam da mesma questão de direito, seja ela de direito material ou processual, foi o principal objetivo do legislador. Nesse aspecto, é inegável que o IRDR detém técnicas capazes de contribuir, em muito, com o Estado Democrático de Direito. Tendo em vista que, a tese jurídica fixada pelo tribunal proporciona segurança jurídica, isonomia e celeridade processual.

O microssistema de resolução de questões repetitivas, formado pelo IRDR e pelos recursos especial e extraordinário repetitivos, deve ser compreendido como um conjunto de normas que se comunicam e se complementam. De modo que, desde que bem interpretadas e aplicadas pelos operadores do direito, podem alcançar ótima resposta à administração e julgamento dos processos repetitivos e assim contribuir para o problema da massificação de demandas.

A pesquisa sobre as resoluções repetitivas são pertinentes em se tratando da continuidade de demandas em massa, o que torna seu estudo necessário, inclusive em relação a efetividade de sua aplicabilidade.

\section{Referências}

Almeida, Marcelo Eugênio Feitosa (2017, out./dez.). Musterverfahren X Pilotverfahren: os regimes de IRDR adotados pelos Tribunais Regionais Federais. Publicações da Escola da AGU. 9, 4, Brasília-DF.

Agravo Interno na Petição n 11.838/MS (2019, 07 agosto). Superior Tribunal de Justiça. Relatora: Ministra Laurita Vaz, Relator p/ Acórdão Ministro João Otávio de Noronha, Brasília. < https://scon.stj.jus.br/SCON/>

Cambi, Eduardo (2001, abril). Jurisprudência Lotérica. Revista dos Tribunais Online, 786, 108-128.

Didier Jr., Fredie \& Cunha, Leonardo Carneiro da. (2016) Curso de direito processual civil: meios de impugnação às decisões judiciais e processo nos tribunais. 13. ed., Salvador: JusPodivm.

Gomes Jr., Luiz Manoel; Ferreira, Jussara Suzi Assis Borges Nasser. (2018, setembro-outubro). Hermenêutica e Uniformização da Jurisprudência: critérios de coerência e integridade da decisão e incidente de resolução de demandas repetitivas. Revista Magister de Direito Civil e Processual Civil, Porto Alegre, 15, 86, $40-55$.

Habeas Corpus $\mathrm{n}^{\circ}$ 195703/RS (2021, 22 janeiro). Supremo Tribunal Federal. Relator: Ministro Alexandre de Moraes, Brasília, DF < https://jurisprudencia.stf.jus.br/pages/search>

Justiça em dados - Painel de Consulta ao Banco Nacional de Demandas Repetitivas e Precedentes Obrigatórios (2021). Conselho Nacional de Justiça. Brasília.

Lakatos, E. M. \& Marconi, M.A. (2003). Fundamentos de Metodologia Científica. São Paulo: Atlas.

Lei $\mathrm{n}^{\circ}$ 13.105, de 16 de março de 2015. Código de Processo Civil. Diário Oficial da União.

Leite, Gisele. (2020, 03 abril). IRDR - Incidente de Demandas Repetitivas no sistema processual brasileiro. <https://www.jornaljurid.com.br/colunas/giseleleite/irdr-incidente-de-demandas-repetitivas-no-sistema-processual-brasileiro>.

Marinoni, Luiz Guilherme. (2019) Incidente de resolução de demandas repetitivas: decisão de questão idêntica x precedente. 2. ed., São Paulo: Thomson Reuters Brasil.

Neves, Daniel Amorim Assumpção. (2019) Manual de direito processual civil. 12. ed. Salvador: JusPodivm.

Oliveira, Fernando Antônio. Incidente de Resolução de Demandas Repetitivas: contexto, teoria e aplicação. Dissertação (Mestrado - Programa de PósGraduação em Direito) - Faculdade de Direito de Ribeirão Preto, Universidade de São Paulo, 2018.

Oliveira, Vallisney de Souza (2016, abril-junho). O Incidente de Resolução de Demandas Repetitivas introduzidono Direito brasileiro pelo Novo Código de Processo Civil. Revista de Informação Legislativa, Brasília, 53, 210, p. 63-80.

Recurso Especial $\mathrm{n}^{\mathrm{o}}$ 1846109/SP (2019, 10 dezembro). Superior Tribunal de Justiça. Relatora: Ministra Nancy Andrighi, Brasília, DF. < https://scon.stj.jus.br/SCON/>

Roque, Andre Vasconcellos (2018, 23 julho). Ações coletivas, IRDR e recursos repetitivos. <http://genjuridico.com.br/2018/07/23/acoes-coletivas-irdr/>.

Silva, Fernando Gabriel de Carvalho e. (2021, junho) Aplicação ao Incidente de Resolução de Demandas Repetitivas (IRDR) do procedimento de distinção (distinguishing) de Recurso Extraordinário e Especial Repetitivos. <https://jus.com.br/artigos/91331/aplicacao-ao-incidente-de-resolucao-de-demandasrepetitivas-irdr-do-procedimento-de-distincao-distinguishing-de-recurso-extraordinario-e-especial-repetitivos $>$.

Silva, Larissa Clare Pochmann da. (2020, maio-agosto) Incidente de resolução de demandas repetitivas (IRDR) e group litigation order (GLO): considerações históricas e requisitos de admissibilidade. Revista Eletrônica de Direito Processual, Rio de Janeiro, 14, v.21, 2, p. $232-251$. 
Research, Society and Development, v. 10, n. 15, e75101522774, 2021

(CC BY 4.0) | ISSN 2525-3409 | DOI: http://dx.doi.org/10.33448/rsd-v10i15.22774

Teixeira, Guilherme Puchalski. (2015, julho-dezembro) Incidente de Resolução de Demandas Repetitivas: projeções em torno de sua eficiência. Revista Eletrônica de Direito Processual, Rio de Janeiro, v. 16, p. 211-239.

Temer, Sofia. (2020) Incidente de resolução de demandas repetitivas. 4. ed. rev., at., amp. Salvador: JusPodivm.

Theodoro Jr., Humberto. (2020, 14 fevereiro) Incidente de resolução de demandas repetitivas: natureza $e$ função. <http://genjuridico.com.br/2020/02/14/resolucao-de-demandas-repetitivas/>.

Theodoro Jr., Humberto. (2015) Enunciados do Fórum da Escola Nacional de Formação e Aperfeiçoamento de Magistrados. < https://www.enfam.jus.br/wpcontent/uploads/2015/09/ENUNCIADOS-VERS\%C3\%83O-DEFINITIVA-.pdf > .

Theodoro Jr., Humberto. (2019) Enunciados do Fórum Permanente de Processualistas Civis.

<https://diarioprocessualonline.files.wordpress.com/2020/05/enunciados-forum-permanente-processualistas-civis-fppc-2020-atualizado.pdf〉.

Salvador 